\title{
Using Segmentation Strategy to Improve the Advertising Campaign For Egyptian Knowledge Bank (EKB)
}

\author{
Faten Ibrahim Awad Khamise
}

Assistant professor at Advertising department, Faculty of Applied arts, Damietta University

\author{
\begin{tabular}{l|l|l|l|l|} 
Submit Date: 2020-06-05 16:30:53 & Revise Date: 2021-03-08 06:24:28 & Accept Date: 2021-04-10 23:24:22
\end{tabular}
}

DOI: 10.21608/jdsaa.2021.31899.1062

\section{KEYWORDS:}

Egyptian Knowledge Bank (EKB), Segmentation strategy, Target marketing, advertising campaign.

\begin{abstract}
:
The research provides an analysis of a design experiment carried out with the third- year students in the advertising department at the Faculty of Applied Arts, Damietta University for the academic year 2018-2019, where students were divided into four groups, each group of which dealt with one of the four gates of the Egyptian Knowledge Bank (children, students, readers, researchers). Each team has thoroughly studied its audience and then developed a number of design ideas that are appropriate to the nature of the target audience. The research also dealt with the definition and foundations of an important concept, which is segmentation strategy. It is one of the important strategies used in the implementation of advertising campaigns that are appropriate to the nature of the institution dealt within the research which is the Egyptian Knowledge Bank.
\end{abstract}

\section{Methodology:}

The research follows the applied methodology based on gathering information for building the theoretical framework for research, while monitoring a number of applied experiences for students for the purpose of analyzing them and identifying the basis used in the segmentation of audience.

\section{Literature Review:}

The newspapers launched the initiative to launch the global scientific content under the patronage of His Excellency the President of the Republic, Abd Al-Fateh Al-Sisi. This initiative was entrusted to the specialized councils of the Presidency of the Republic.This initiative is based on providing the global scientific content of every Egyptian citizen under the principle of "Towards a society that learns, thinks and innovates".

This initiative launched under the name of "Egyptian Knowledge Bank" and includes the creation of a huge digital library containing thousands of the latest scientific journals, e-books, documentaries and educational libraries, in addition to the curriculum and the databases in various branches of knowledge.

The aim of this initiative is to establish a culture of research and knowledge of the latest scientific knowledge around the world for all those seeking documented knowledge and scientific information in Egypt. 


\section{INTRODUCTION:}

Nearly every company and organization advertises to extend awareness, reach deals goals, and construct brand loyalty. Yet, due to the unavoidable nature of advertising, reaching an audience has ended up more complicated and less successful. An expanding number of marketers are depending on point by point, targeted advertising to reach the foremost likely audience of a specific brand, service or idea.

Modern information and innovation now permit companies and advertising agencies to coordinate messages to particular audiences. This process, known as target advertising, is critical in order to fulfill the most noteworthy return on investment and properly position an item within the minds of the planning group of the audience. Target marketing is characterized as a common methodology utilized to recognize clients sharing similar characteristics, and reach them through those characteristics (Johnson \& Grier, 2011).

"Egyptian Knowledge Bank", is one of the greatest assignments throughout the whole nation that's included with knowledge, it provides tremendous sources for knowledge and culture for free, to all Egyptians. This project presents all Egyptian inhabitants with on-line access to exceptional research and instructional sources (books, periodicals \& media) within Egypt.

The main portal for the EKB website has four sub-portals to address a wide range of internet users; the children, students, researchers and general readers' portals, which means that all segments of society are targeted at the services provided. (EKB, n.d., p. 9/2/2019)

Preservation of this knowledge is a prime task; however, it is a need to market these resources which possess by the EKB. Therefore the issue of marketing these services is problematic since we must ask what exactly are we trying to market and to whom? What are the best strategies used in advertising campaigns that are appropriate to the nature of the organization? How can the target audience be divided into each of the four portals, and how can each category be addressed in a manner that is appropriate to its nature? What are the scientific foundations for segmenting the target audience?

\section{What is Market Segmentation?}

The world is made up of many various audiences, each with their own set of needs and behaviors. Segmentation looks to complement audiences with products or services that fulfill their individual set of needs and behavior patterns. (Martin, 2011)

Market segmentation is defined as a common methodology used to identify audiences sharing similar characteristics, and reach them through those characteristics. (Johnson \& Grier, 2011)

It is one of the most important and powerful marketing concepts. (Hollerbach, 2009)

It is a process of dividing the market of prospect audiences into several groups and segments on the base of definite characteristics. The member of these groups share similar characteristics and generally have one or more than one side common among them. Without target advertising, most of the advertising uses would fail in reaching a market that does not have the highest potential to become active audiences. (Iyer, Soberman, \& Villas-Boas, 2005) .

\section{The Reason for Segmenting Audience Mar- kets:}

The aim of marketing is to match the real needs and desires of audiences with the offers of companies to satisfy those needs and desires. This matching process benefits audiences and companies, and improve an organization's marketing planning process. There are numerous reasons as to why market segmentation is preferred as a base for planning an advertising campaign for EKB. One of the main reasons is to create a specific marketing mix for each segment and serve them accordingly. (Dolnicar, Grün, \& Leisch, 2018)

\section{Bases Of Segmenting Audiences:}

Segmenting is separating a group into subgroups according to some specific "bases". These bases include age, gender, etc. and psychographic aspect as attitude, interest, values, etc.

The major segmentation variables are:

- Geographic segmentation

- Demographic segmentation

- Psychographic segmentation

- Behavioral segmentation ( Kanesan, Ismail, \& Krishnan, 2018) 


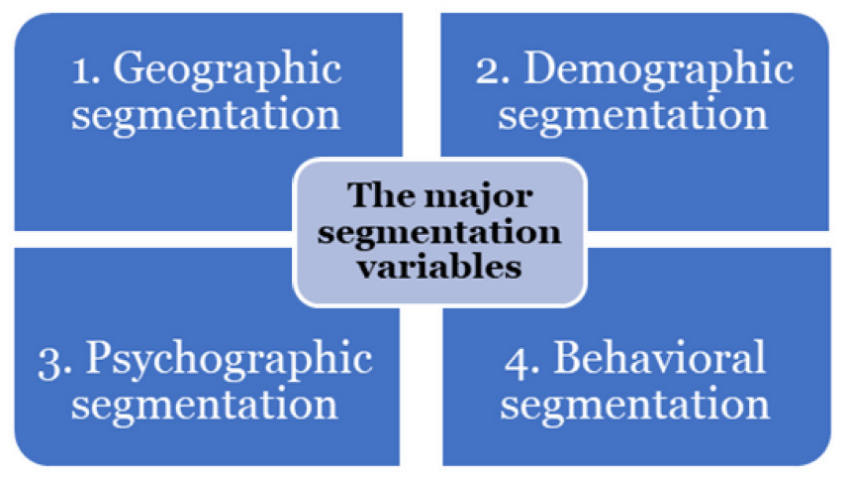

Fig. (1) Major segmentation variables The shape was designed by the researcher

\subsection{Geographic Segmentation:}

Geographic segmentation means dividing the market into different geographical units such as regions, cities, or neighborhoods. ( Kanesan, Ismail, \& Krishnan, 2018)

It is based on the belief that audiences who live within the same region share a few common wants and needs and those wants and needs could be very distinctive from the audiences who are living in other regions. (Martin, 2011)

Egyptian Knowledge Bank as a source of knowledge, culture and the dissemination of science, the Psychographic segmentation does not represent much importance when planning advertising campaigns, as the requirements of culture and science are not affected by the geographical region within the Arab Republic of Egypt.

\subsection{Demographic Segmentation:}

Demographic segmentation divides the advertisement into groups on the basis of variables such as age, education, gender, income, family life cycle, profession, religion, generation, and social class. ( Kanesan, Ismail, \& Krishnan, 2018).

As mentioned before, the EKB portal has four sub-portals to address a wide range of audience; the children, students, researchers, and general readers' portals, which means that we need to send different messages to different audiences, so Demographic variables are the most suitable base of EKB for distinguishing their audiences groups. The reason is that the audience's wants, preferences, and usage rates are often associated with demographic variables.

\subsection{Psychographic Segmentation:}

Psychographic segmentation was created by marketing researchers to relate identify with brands. Psychographics is classified as "the study of iden- tity, values, attitudes, interests, and lifestyles." Organizations need to know their audience's habits to successfully interface with them and for the audiences to identify the organization's products or services. (Martin, 2011).

Children, Students, Researchers and General readers have different attitudes and interests, which means that Psychographic Segmentation should be taken into account when planning advertising campaigns for EKB.

\subsection{Behavioral Segmentation:}

Behavioral Segmentation is based on the actual audience's behavior towards services. Some behavioral variables include required benefits, Usage rate, Brand loyalty, User status, Readiness to buy, and opportunities. (Goyat, 2011).

There is no doubt that the needs of students and researchers for the sources of science and knowledge are much higher than the needs of children and readers, so their Usage rate of EKB varies from group to group and also their required benefits.

\section{Benefit Segmentation:}

Benefit segmentation is defined as a form of market segmentation based on the contrasts in particular benefits that different groups of audiences are looking for in a product or an organization. One of the five common segmentation strategies, its objective is to characterize particular niches that require custom- tailored advertising (definition/ benefit-segmentation, 2020).

Benefit segmentation based on the segmentation audiences according to what particular benefit of the organization appeals to them. It is a tool for improving communication with selected audiences by selecting topics which progress your chance of catching the attention of your prospective audiences and of involving them in your advertising. In our experiment, Benefit segmentation is used to suggest that for EKB services what is the services, advantages or benefit that different audiences get. Different audiences look for different services and the designer needs to understand each segment and accordingly develop his messages for each group.

Benefit segmentation helps third-year students in their project to identify audiences on the basis of the values they looking to take out from EKB. By using benefit segmentation, the impact of advertising on EKB services could be increased by at 
least two- or three-fold. (Frochot \& M. Morrison, 2012).

\section{Planning Of An Advertising Campaign for EKB:}

The main goal of advertising for EKB services is to attract the audiences' attention and analyze the impact of advertising on their behavior so, it is necessary to notify a complex of behavior, psychological, communication and selling factors.

Advertising effectiveness relies on both the quality of the services being advertised and the quality of the message sent by the ad. and also the media in which the ad appears. (Shokri, 2014).

\subsection{Advertising Campaign:}

Advertising campaign is the group of promotional activities, developed in correspondence with the marketing agenda and aimed at audiences, representing proper market segments, so as to cause their response and find a solution for the strategic objectives of an organization.

Advertising Campaign is an expression used for a well-organized course or a series of actions. A multidimensional strategy is planned by using several media. Designing an advertising Campaign is not only to create a nice layout for the aim of aesthetics or creativity, but it has to be also useful. It is usually well planned and designed after deep thinking and thorough brainstorming sessions.

All design elements ought to be interconnected and harmonious in order to succeed in clarifying the purpose of delivering the message. The idea should be given a theme to make it effective so that audiences should respond to it. So that the campaign design is considered successful. (Ahuja, 2011).

\subsection{Innovative Poster Design:}

For EKB Library, audience satisfaction is the key ingredient of a good marketing strategy. The main segmentation of EKB marketing is their audience, i.e. students, faculty members, staff,

Research scholars, General users of the library, International students studying in various courses, etc. It is difficult to work out a single marketing strategy for all the categories of segments. However, it will be worthwhile to formulate different strategies for an individual group of segments. (S. K. Patil, 2014, p. 250)

In undertaking marketing and promotion activities, the target market was segmented into four namely:
(1) Children
(2) Students
(3) Researchers
(4) General readers

Accordingly, the third- year students (who are 24 students) were divided into four groups, each group consists of 6 students, and each individual in the group undertakes to develop a number of advertising ideas for one of the four portals in a manner that is appropriate to the nature of the target audience, as follows:

- $\operatorname{Group}(\mathrm{A})$ : responsible for Children sub-portable

- Group (B) : responsible for Students sub-portal

- Group ( C) : responsible for Researchers sub-portal

- Group ( D) : responsible for General readers sub-portal

While planning a strategy for a campaign, each group have to study their target audience and learn about its most important characteristics as follows:

\section{Demographic Segmentation:}

- Age ranges: by segmenting the target audience according to the target age, each group will be able to create better advertising ideas and communication strategies and get better conversion rates.

- Education: This is done because EKB offers services that satisfy a mutual interest to these segments, students of early-stage, university students, researchers...each differs in their needs and interest

- Occupation: influences the Subscription decision of the target audience. There are even many Services provided by EKB which cater to an audience engaged in a specific occupation.

Behavioral Segmentation:

- Required Benefits: Benefit segmentation focuses on the advantages of EKB services and what audiences would respond to stated benefits. Usage segmentation identifies groups who already use the service and advertise specifically to those audiences.

- Usage Rate: EKB usage also acts as a segmenting basis. The audience can be labeled as heavy, medium or light users of EKB services. The audience can also be segmented on the basis of their awareness of the EKB services. 
Besides, each group of the four must have answers for a number of questions:

1. Who is the decision maker for registration on the EKB website?

2. What are the main reasons that lead the audience to subscribe to the service? (What are the most important problems and needs facing each category?).

3. What are the advantages offered by the bank to each of the four categories that contribute to meeting their needs?

\begin{tabular}{|c|c|c|c|c|}
\hline & $\begin{array}{c}\text { Group (A) } \\
\text { Children Sub-Portal }\end{array}$ & $\begin{array}{c}\text { Group ( B) } \\
\text { Students Sub-Portal }\end{array}$ & $\begin{array}{c}\text { Group ( C) } \\
\text { Researchers sub-portal }\end{array}$ & $\begin{array}{c}\text { Group ( D) } \\
\text { Readers Sub-Portal }\end{array}$ \\
\hline Age ranges & Babies, Children & Adolescents, Adults & $\begin{array}{l}\text { Adults, Middle-Age, } \\
\text { And Seniors }\end{array}$ & $\begin{array}{l}\text { Adolescents, } \\
\text { Adults, Mid- } \\
\text { dle-Age, And } \\
\text { Seniors }\end{array}$ \\
\hline Education & $\begin{array}{l}\text { Preschool \& first } \\
\text { stages of primary } \\
\text { school }\end{array}$ & $\begin{array}{l}\text { School \& under- } \\
\text { graduate students }\end{array}$ & $\begin{array}{l}\text { Researchers at universi- } \\
\text { ties \& research center }\end{array}$ & $\begin{array}{l}\text { Miscellaneous } \\
\text { education levels }\end{array}$ \\
\hline Occupation & - & Student & Researchers & $\begin{array}{l}\text { Miscellaneous } \\
\text { occupation }\end{array}$ \\
\hline $\begin{array}{l}\text { Required } \\
\text { Benefits }\end{array}$ & $\begin{array}{l}\text {-Encourage a lifetime } \\
\text { of learning } \\
\text {-Improves reading } \\
\text { skills } \\
\text {-Broadens minds } \\
\text { and develops empa- } \\
\text { thy } \\
\text {-Develops imagina- } \\
\text { tion } \\
\text {-Reading is fun! }\end{array}$ & $\begin{array}{l}\text { - Instant access to } \\
\text { educational content } \\
\text { anywhere and at } \\
\text { any moment }(24 / 7) \\
\text { through the use of } \\
\text { digital devices such } \\
\text { as smartphones, } \\
\text { tablets or laptops }\end{array}$ & $\begin{array}{l}\text {-Instant access to } \\
\text { educational content } \\
\text { anywhere and at any } \\
\text { moment } \\
\text {-More than scholarly } \\
\text { content with various } \\
\text { validation processes }\end{array}$ & $\begin{array}{l}\text {-A heightened } \\
\text { amount of resourc- } \\
\text { es choice } \\
\text { - Shareability } \\
\text { - Unlimited Stor- } \\
\text { age Space }\end{array}$ \\
\hline Usage Rate & Medium or light & Medium Or Heavy & Heavy Or Medium & Medium Or Heavy \\
\hline Question 1 & Parents & Himself & Himself & Himself \\
\hline
\end{tabular}




\begin{tabular}{|c|c|c|c|c|}
\hline Question 2 & $\begin{array}{l}\text { The need to spend } \\
\text { leisure time usefully } \\
\text { and enjoyably } \\
\text {-The need to Im- } \\
\text { prove reading habit } \\
\text { and skills develop- } \\
\text { ment } \\
\text {-Fun and useful edu- } \\
\text { cational resources }\end{array}$ & $\begin{array}{l}\text { - The need to edu- } \\
\text { cational resources } \\
\text { suitable for the } \\
\text { Egyptian curricu- } \\
\text { lum } \\
\text { - The lack of a } \\
\text { sufficient number } \\
\text { of libraries and ed- } \\
\text { ucational resources } \\
\text { in all regions or all } \\
\text { times } \\
\text { - High costs of } \\
\text { good educational } \\
\text { resources }\end{array}$ & $\begin{array}{l}\text { - High costs of research } \\
\text { sources and global pub- } \\
\text { lishing houses } \\
\text {-Unavailability of reli- } \\
\text { able sources }\end{array}$ & $\begin{array}{l}\text { - The lack of a } \\
\text { sufficient number } \\
\text { of libraries and } \\
\text { reading resources } \\
\text { in all regions or all } \\
\text { times } \\
\text { - reading resources } \\
\text { are not available all } \\
\text { time }\end{array}$ \\
\hline Question 3 & $\begin{array}{l}\text { Free subscription } \\
\text {-All resources are } \\
\text { under good control } \\
\text {-Resources content is } \\
\text { suitable for age rage. }\end{array}$ & $\begin{array}{l}\text {-Free high- quality } \\
\text { reference materials } \\
\text {-Instant access to } \\
\text { educational content } \\
\text { anywhere and at } \\
\text { any moment ( } 24 / 7) \\
\text { through the use of } \\
\text { digital devices such } \\
\text { as smartphones, } \\
\text { tablets or laptops }\end{array}$ & $\begin{array}{l}\text {-Free high- quality } \\
\text { reference materials } \\
\text { - Instant access to } \\
\text { educational content } \\
\text { anywhere and at any } \\
\text { moment } \\
\text { The list of publishers } \\
\text { is full of prominent } \\
\text { entities as Britannica, } \\
\text { Elsevier, National Geo- } \\
\text { graphic, Springer, Wil- } \\
\text { ley, Oxford University } \\
\text { Press, .....and others }\end{array}$ & $\begin{array}{l}\text {-A heightened } \\
\text { amount of resourc- } \\
\text { es choice } \\
\text { - Unlimited Stor- } \\
\text { age Space } \\
\text { - Instant access } \\
\text { anywhere and } \\
\text { at any moment } \\
\text { ( } 24 / 7) \text { through } \\
\text { the use of digital } \\
\text { devices such as } \\
\text { smartphones, tab- } \\
\text { lets or laptops }\end{array}$ \\
\hline
\end{tabular}

Table (1) the relation between major segmentation variables and EKB audience 


\section{Design Results :}

- First : Design Samples From Group (A) Children Sub-Portal:
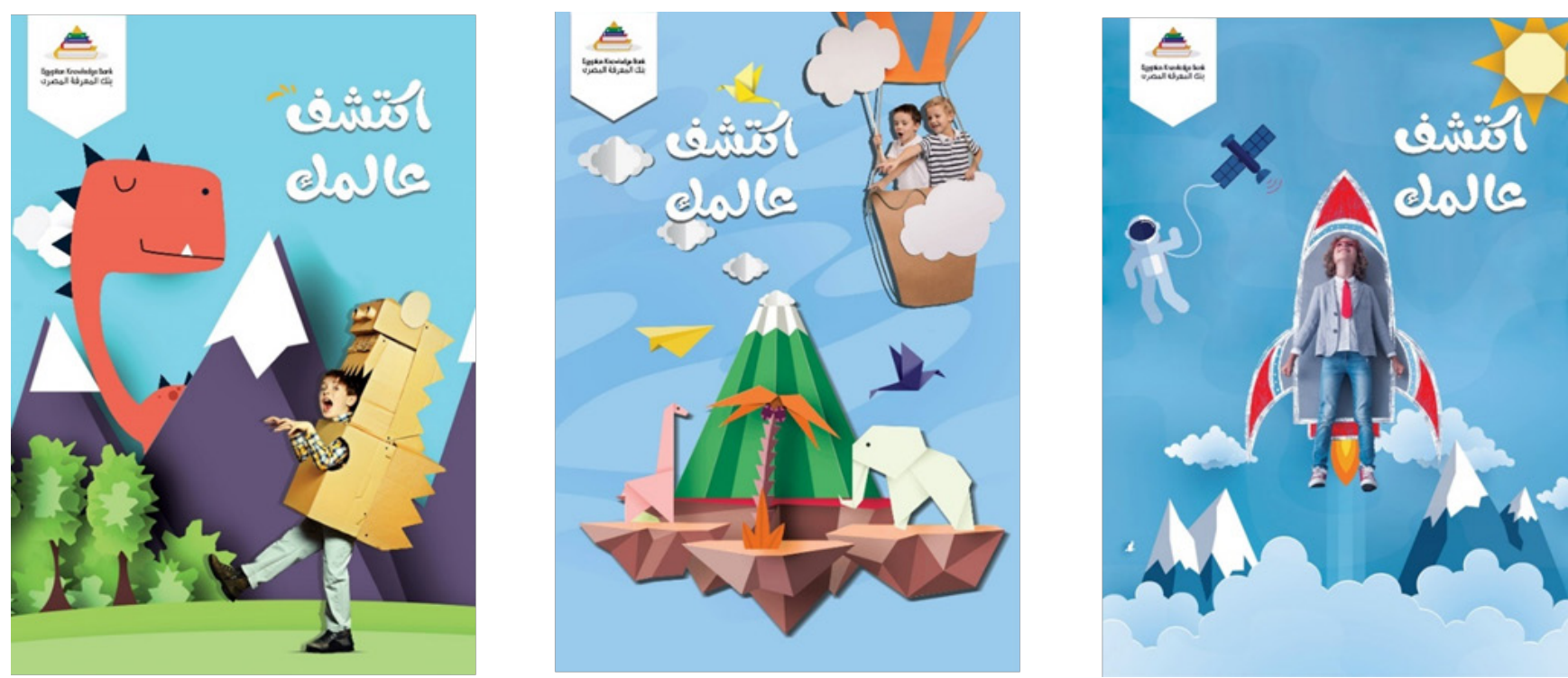

Fig (2) Done by student: Ola El-Khawaga Group (A) Children sub-portal
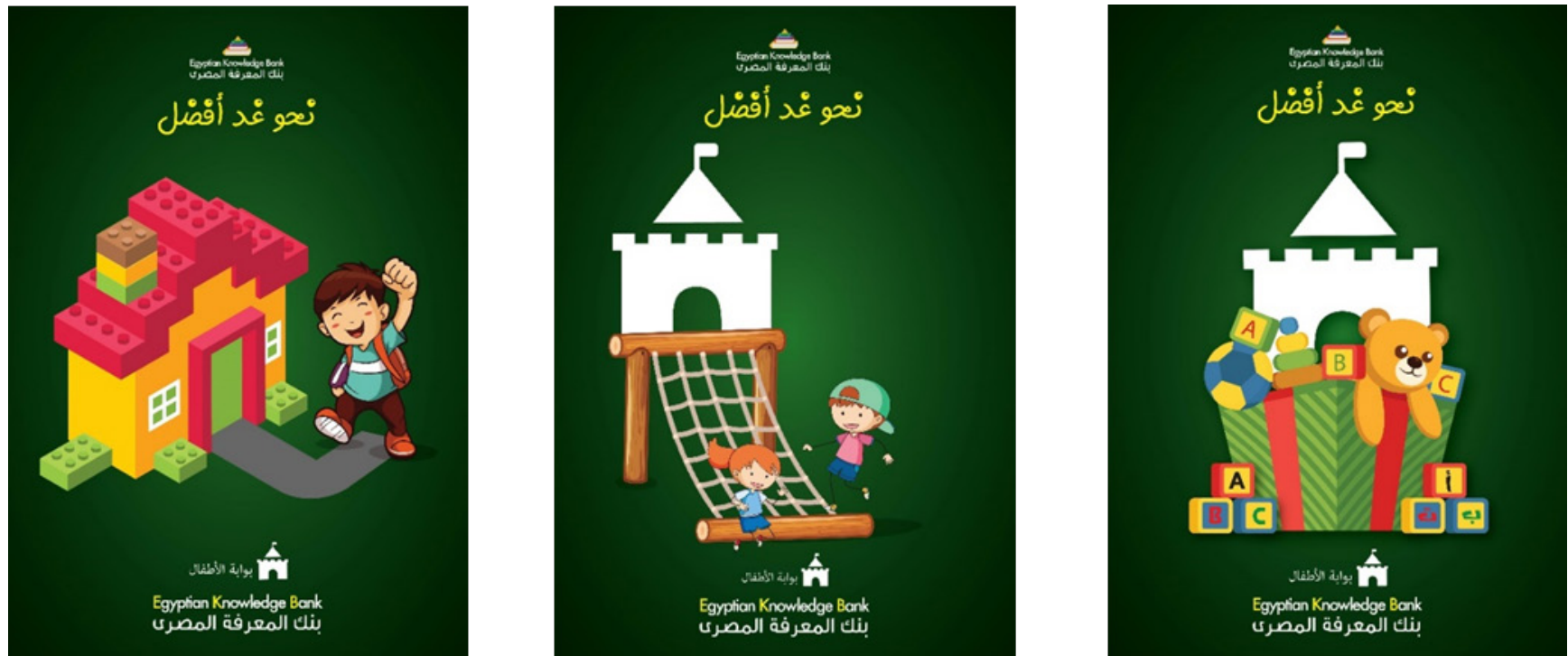

Fig (3) Done by student: Aya El-Baaz - Group (A) Children sub-portal 
- Second: Design Samples From Group (B) Students Sub-Portal:
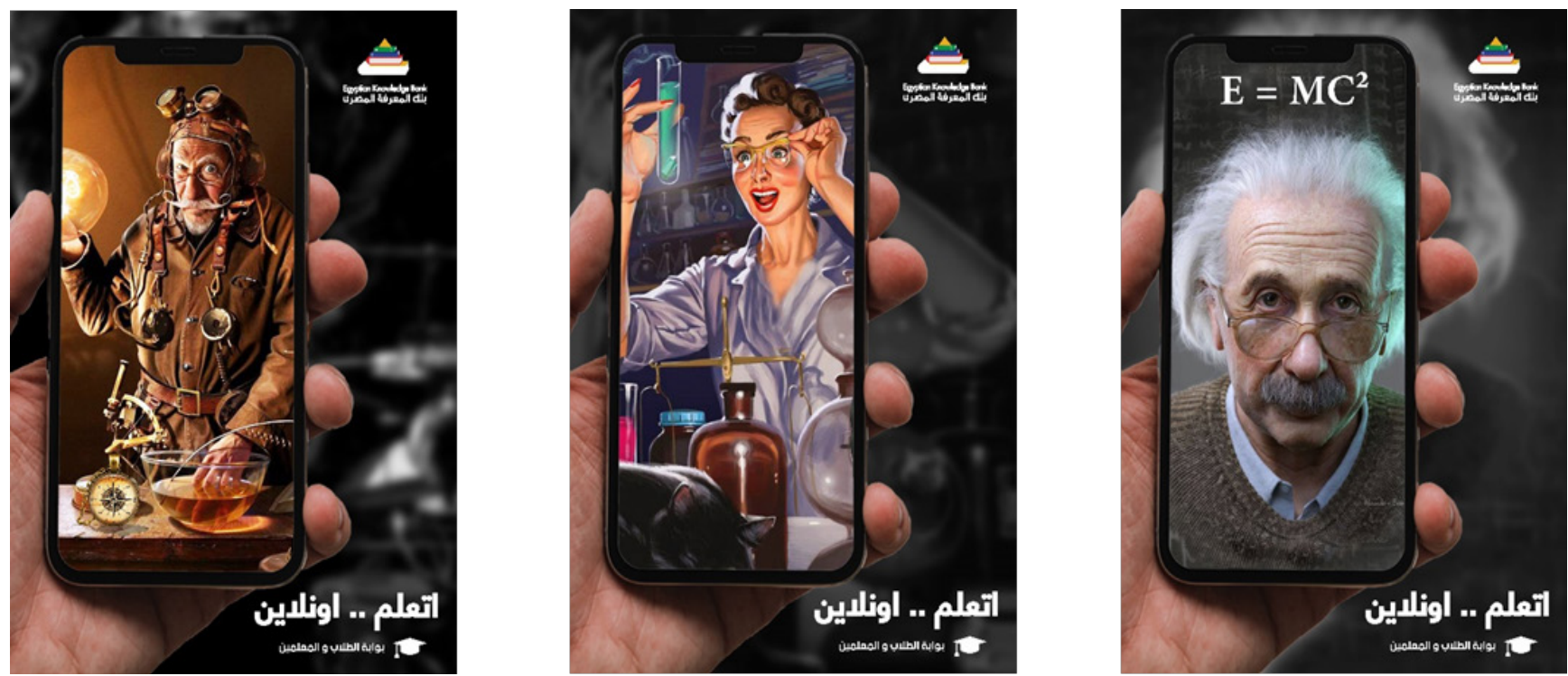

Fig (4) Done by Student: Reham Negm- Group (B) Student Sub- portal
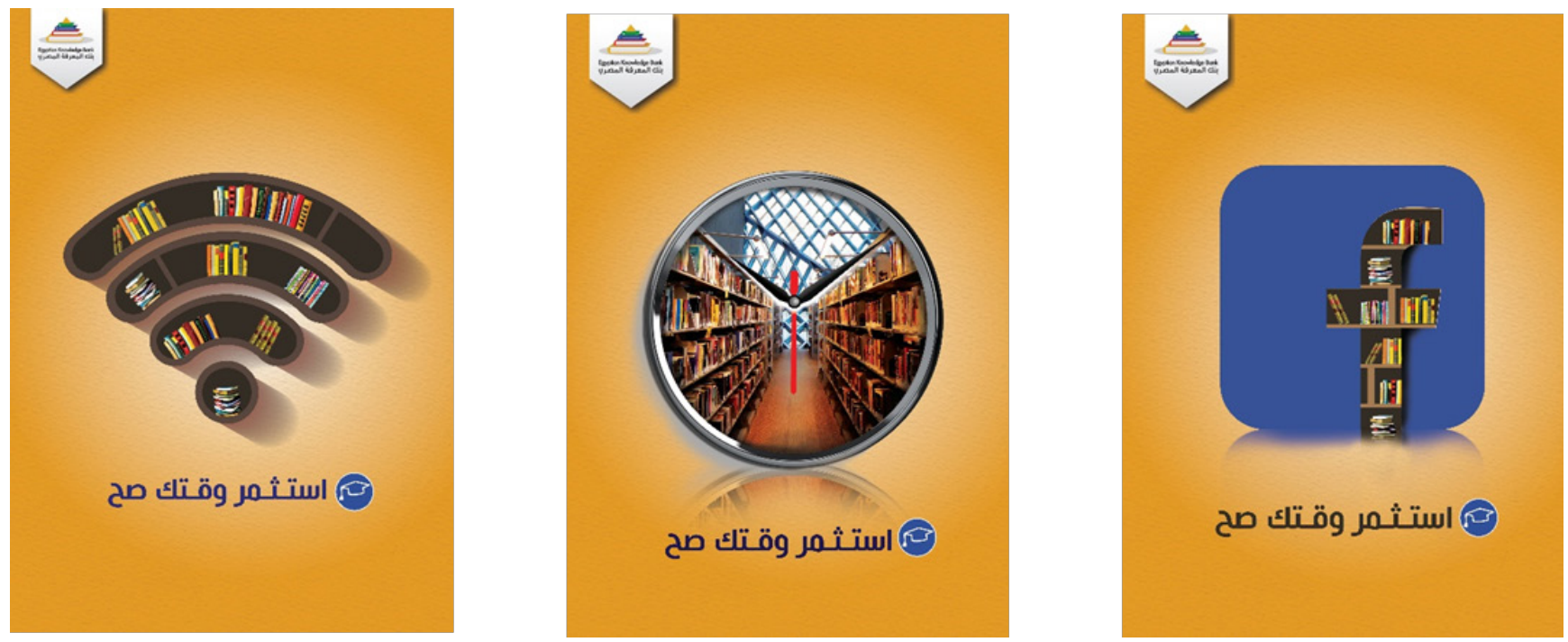

Fig (5) done by Student: Nourhan Chahin - Group (B) Student Sub- portal 
- Third: Design Samples From Group (C) Researchers sub-portal:
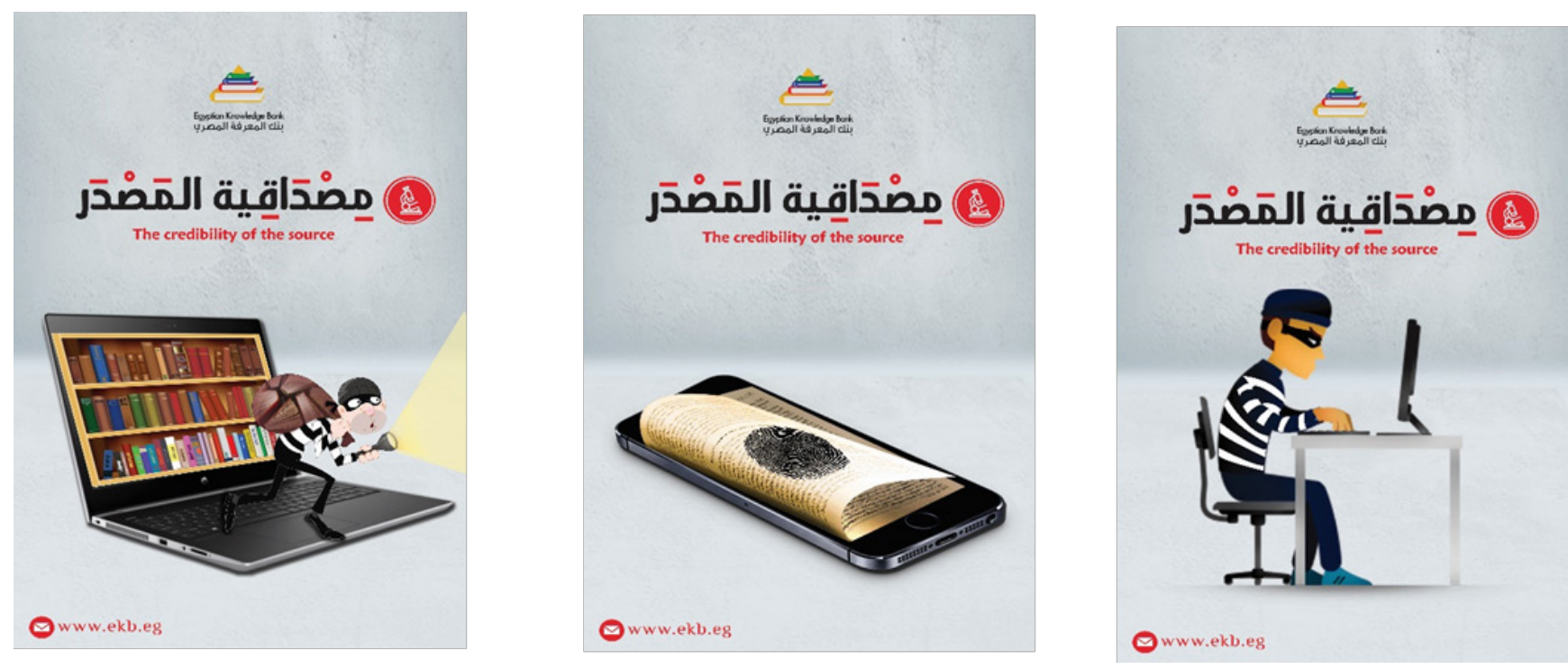

Fig (6) Done by Student: Asmaa Mohamed- Groub (C) Researchers Sub- portal
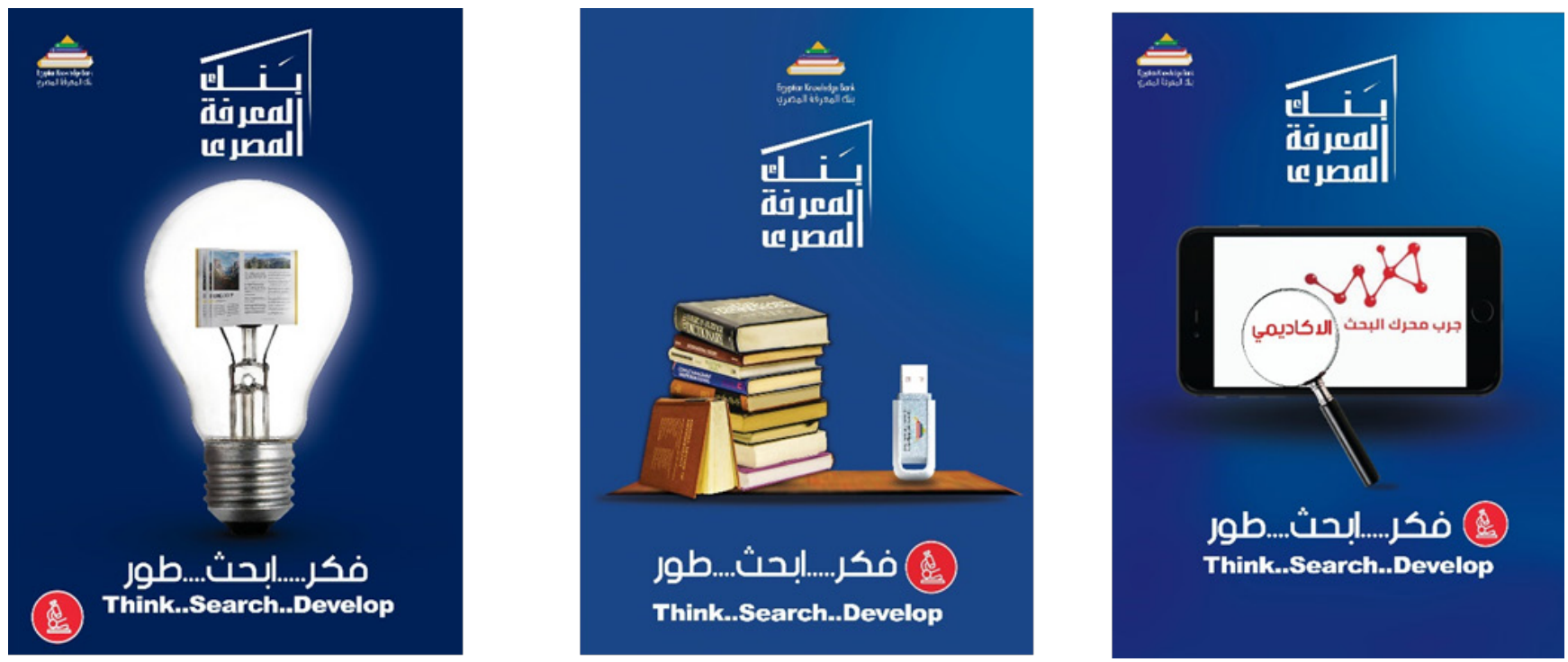

Fig (7) Done by Student: Enas Darwish - Groub (C) Researchers Sub- portal 
- Fourth: Design Samples From Group (D) General Readers sub-portal:
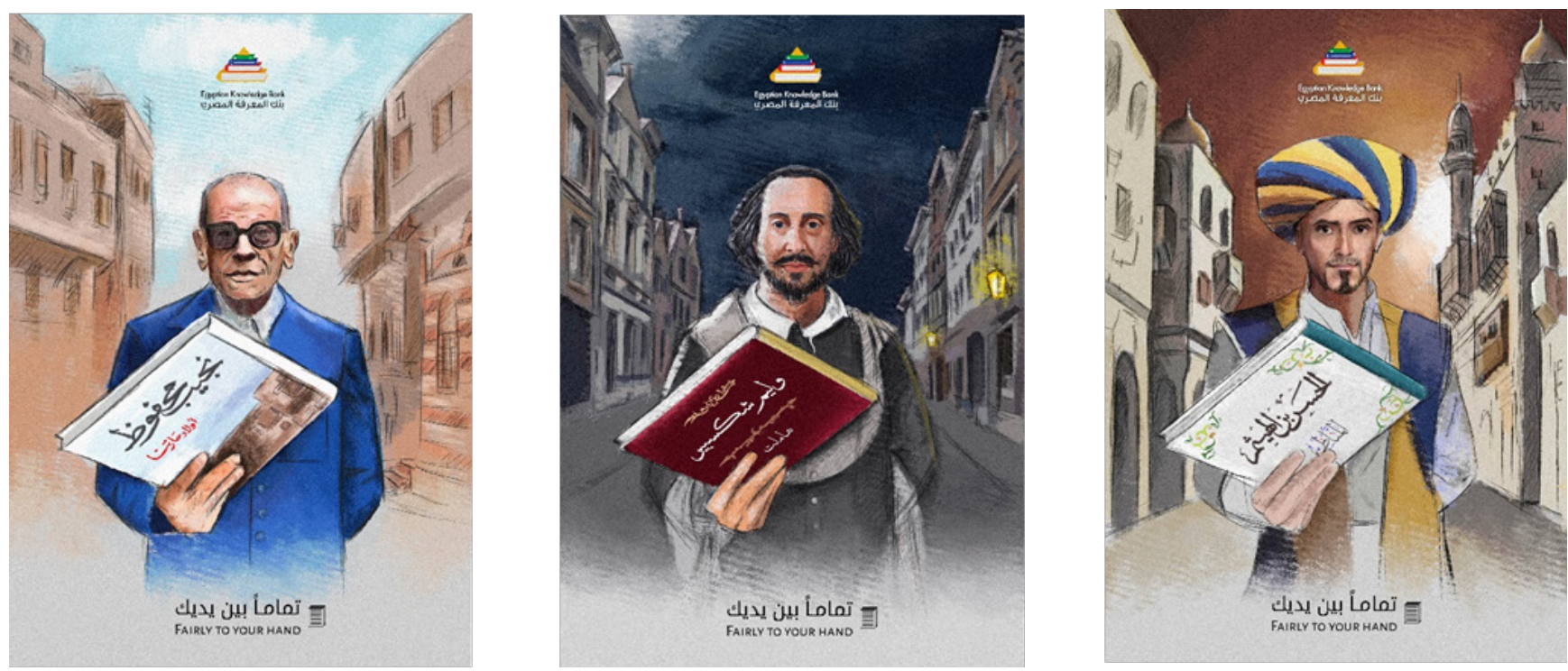

Fig (8) Done by Student: Ahmed Radwan - Groub (D) General Readers Sub- portal
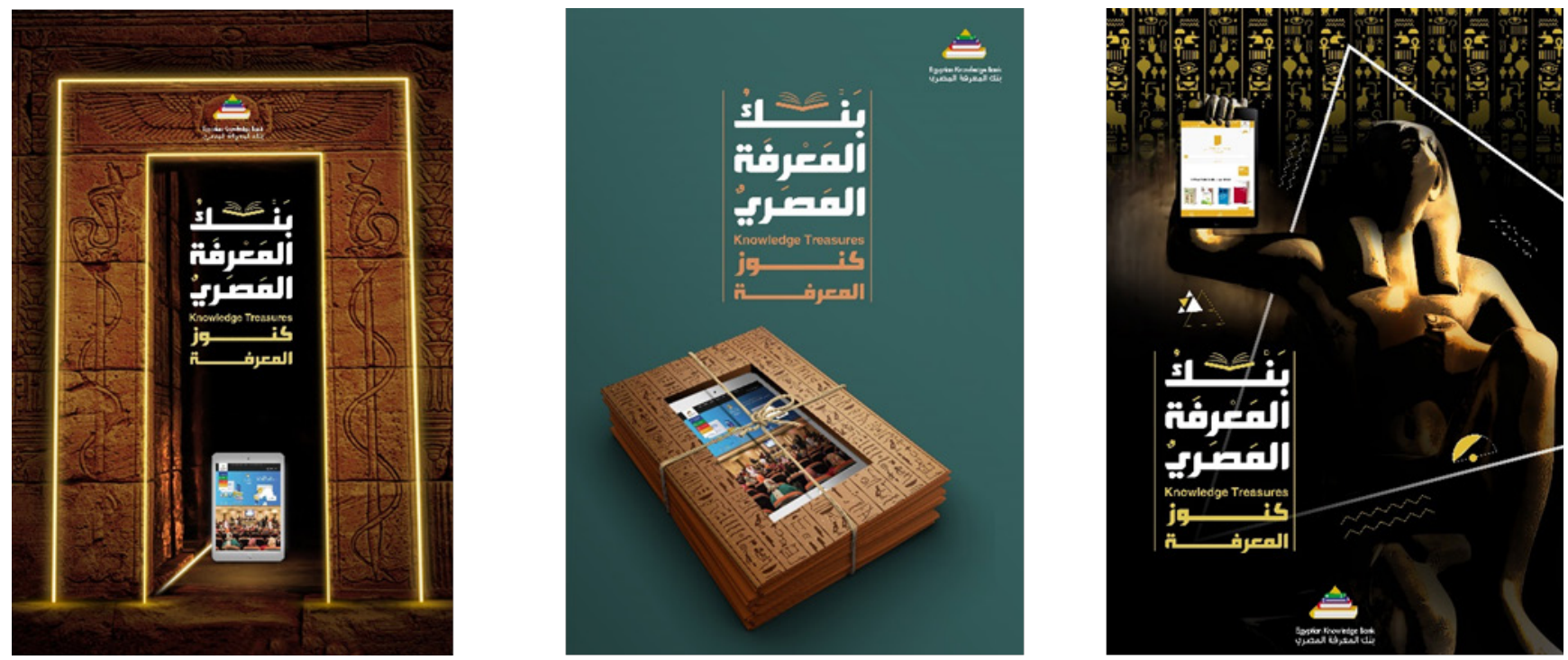

Fig (9) Done by Student: Fathy Elshaer - Groub (D) General Readers Sub- portal 


\section{Research problem:}

How to use the Segmentation strategy to increase the awareness about the EKB?

What is the role of Target marketing, Advertising campaign in improving the image of the EKB and its services?

\section{Objectives of the study:}

- To find out the target advertising effect on campaign success.

- To find out the effect of using Segmentation strategy to increase the effectiveness of the advertising campaign.

- To formulate different advertising campaign for individual group of audience segments.

- To study the creative poster designs done by students after studying each target group

\section{Conclusion:}

By creating a successful advertising campaign, you increment the probability of a positive return on your advertising venture.

Demographic and psychographic variables for the audience segmentation have dominance in planning and improving the advertising campaign strategy. Additionally, segmentation is completely dependent on all four traditional bases not on a single one.

This encourages that there's a requirement to promote research in the market segmentation region to find out, the rule theory of market segmentation.

While each campaign may have a specific message and use different channels and make varied objectives, success requires targeting.

\section{References:}

\section{Books:}

Ahuja, K. (2011). Towards a New Age Graphic Design (First Edition ed.). National Council of Educational Research and Training,New Delhi, 2011.

Dolnicar, S., Grün, B., \& Leisch, F. (2018). Market Segmentation Analysis Understanding It, Doing It, and Making It Useful. Springer Nature Singapore Pte Ltd.

\section{Journals:}

Frochot, I., \& M. Morrison, A. (2012, november 14). Benefit Segmentation: A Review of Its Applications to Travel and Tourism Research. Journal of Travel \& Tourism Marketing, 9(4), 21-45.

Goyat, S. (2011). The basis of market segmen- tation: a critical review of. European Journal of Business and Management, 3(9), 45-54.

Hollerbach, K. L. (2009). The impact of market segmentation on African American frequency, centrality, and status in television advertising. Journal of Broadcasting \& Electronic Media, 53(4), 599-614.

Iyer, G., Soberman, D., \& Villas-Boas, J. (2005, July 01). The targeting of advertising. Marketing Science, 24(3), 461-476.

Johnson, G., \& Grier, S. (2011). Targeting without alienating: Multicultural advertising and the subtleties of targeted advertising. International Journal of Advertising, 30(2), 233-258.

Kanesan, S., Ismail, N., \& Krishnan, K. (2018, April). Identifying Market Segments andTargets forMarketing Strategy Plan ofCoca-Cola Company inMalaysia. International Journal of Business and Management Invention, 7(4), 77-80.

Martin, G. (2011, June). The Importance Of Marketing Segmentation. American Journal of Business Education, 4(6), 15-18.

S. K. Patil, P. P. (2014). Library promotion practices and marketing of Library services: A. Social and Behavioral Science, 133, pp. 249 - 254. Retrieved from ScienceDirect

Shokri, S. A. (2014). Role of Psychological Factors on Advertising Effectiveness. International Journal of Academic Research in Business and Social Sciences, 4(10), 449-454.

\section{Websites:}

definition/benefit-segmentation. (2020, january 17). Retrieved from businessdictionary: http:// www.businessdictionary.com/definition/benefit-segmentation.html 17/1/2020

EKB. (n.d.). http://www.ekb.eg/about-us. Retrieved february 9, 2018, from www.ekb.eg: http://www.ekb.eg 